\title{
Design Study on Green Sports Building Based on BIM
}

\author{
Shaogang $\mathrm{Zhu}^{1,2,{ }^{*}}$ and Yunyu $\mathrm{Tu}^{2}$ \\ ${ }^{I}$ College of Applied Science of Jiangxi University of Science and Technology, China; ${ }^{2}$ College of Physical Education, \\ GanNan Normal University, China
}

\begin{abstract}
Under the background of sustainable development, the energy-consuming equipment and application mode of building system have changed to some degree. BIM's green building is the priority in design currently. BIM reintegrates the process of buildings design and the involved life cycle management of building is focused and affected by green building design. Building information model covers the information of geometry, physics and topology. Geometrical information directly reflects the shape of buildings in three-dimensional space and physical information describes the physical property of various components, such as thermal coefficient, etc. And topological information includes the correlation among various components. However, due to the influence of multiple elements and lack of the support of appropriate platform, this method faces some difficulties and obstacles, such as weak compatibility and expandability, low integration level of information, etc., which results in many problems in sports building design. This paper will analyze design pattern in detail by studying the key points that BIM technology combines green building design.
\end{abstract}

Keywords: BIM, design essentials, green sports building.

\section{INTRODUCTION}

Building system is a complex management system, including building space system, maintenance structure system, construction equipment system, etc. Due to complex construction system, various complex factors must be taken into account during design process. Traditional building design has specific requirements for function, form and space. With the continuous development of green building, original design methods cannot satisfy the actual requirements of buildings. Therefore, development mechanism must be defined during design process. The combined process of key physical and functional performance should be explored in a digital way before the project is implemented. As BIM system is a form of informatization development, if the influencing mechanism is not distinct, new design methods must be proposed.

\section{IMPACT OF BIM TECHNOLOGY ON BUILDING MODE}

\subsection{Variation Trend of the Thinking Mode of Building Design}

To realize ideal design effect, sports building design must have definite construction mode. As human's thinking variation exerts impact on the change of building system, the application mode of thinking must be defined during design process. Besides, building design form is changed gradually because different design media adopt different technological means and expression methods. During design process, the importance of abstract language must be defined, thus extending graphic language positively. Secondly, efficient analysis should be conducted to the design mode that has formed and the content of picture should be reviewed during the direct graphical analysis and design process. And computeracy system should be applied in architecture to assess and deepen the scheme if necessary [1].

\subsection{Changing Process of Building Design}

The original design system dated from the 1950s and the relation among analysis system, comprehensive assessment system and optimization system is involved during design process, so as to efficiently analyze and quote the features of application. The problems during traditional design process must be defined, based on which, equipment engineer determines appropriate system. According to the existing traditional design process in China, designers successively participate in fulfilling all design tasks. Hence, it can be regarded as a "linearizing" process, which makes it extremely difficult to realize the optimization of final stage as well as real optimization because building performance is restricted to conventional level. The building construction process is shown as in Fig. (1).

\section{ANALYSIS ON THE RELATION BETWEEN BIM TECHNOLOGY AND GREEN BUILDING DESIGN}

\subsection{Green Building Design Form of CAD}

With the continuous optimization of building design mode in China, if the effective outward appearance design of building is neglected, passive design methods should be adopted. During the design process of building, the energy efficiency design of building should be emphasized and the best design scheme should be selected. During the construction 


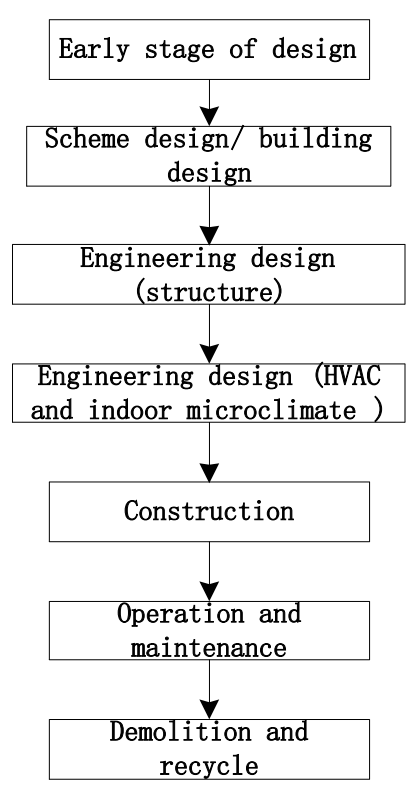

Fig. (1). Analysis on construction process at construction stage.

process of CAD, the impact resulting from other factors must be taken into account at detailed design stage because separate design mode is adopted at the conceptual design stage. The design at early stage exerts a bigger impact on building environment and its overall impact is expanded gradually along with the continuous development of design stage. The operation application system and application software not only require complex knowledge system, but also regard the professional management procedure as the media. And then professional training personnel connect the input data and procedure reasonably and efficiently. During the design process of two-dimensional traditional system, energy calculation is always arranged at the last design stage. And during the process of professional simulation operation, energy must be taken as a symbolic gesture to reduce its impact on green building design [2].

\subsection{Combined Application of BIM and Energy Analysis Software}

The application of BIM design system will benefit architects and engineers and the efficient transformation of data can be used to analyze and apply energy consumption information if necessary. As BIM possesses automatic update procedure, relevant project personnel should be contacted to improve work efficiency and design precision. Besides, BIM

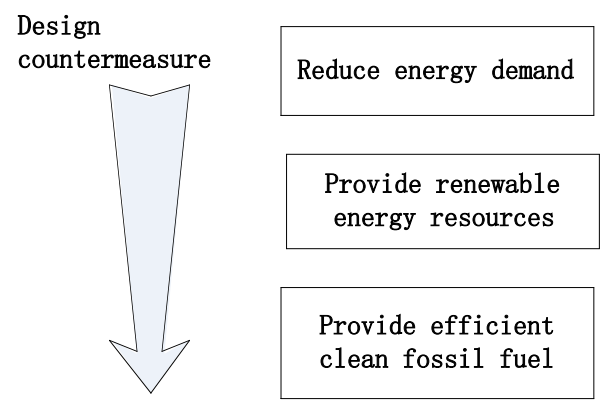

is able to provide simulated analysis data for the lighting, ventilation, heat supply, carbon footprint, etc. of building, creating real "green building" through sustainable design. The application system offers necessary development direction and approach to building designers and assists them in designing green building by using software tool and combining simulated building data without additional efforts [3].

\subsection{Application of BIM Technology in Green Sports Building Design}

To reduce the emission of carbon dioxide, the existing energy available must be analyzed efficiently. The impacts of many reasons result in low utilization of resource. To reduce the waste of resources, new energy must be developed positively and new technology and method should be adopted to efficiently adjust the project content. When the project is located in different places, it will be affected seriously by the factors of local resource, climate and orientation. Thus appropriate technology should be selected in accordance with the local conditions, local resource and raw material should be utilized and applicable construction technology and skill should be adopted. And a reasonable analysis should be made to it according to the design procedure of energy and environment construction idea as well as corresponding technology. The specific analysis is shown as in Fig. (2).

There is a definite relation between material growth need and the variation trend during building construction process. Green building focuses on the building constructed when resources are deficient, and the circulation and reutilization involved can be blended in urban ecological development system. In complex design system, designers must consciously change their design concepts and traditional design process, thus better balancing the relation among the function, aesthetics and performance of buildings.

\section{INTEGRATES DESIGN BASED ON BIM}

\subsection{Design Program Analysis at Early Stage}

During the early design process, design objective must be defined, including wind energy, solar energy, landscape and urban development planning mechanism and other factors. And efficient design and application must be in strict accordance with the development requirements of proprietor as well as design plan. Relevant data provided by proprietor must be able to prove the reliability of energy system. Meanwhile, design is conducted based on the change mode
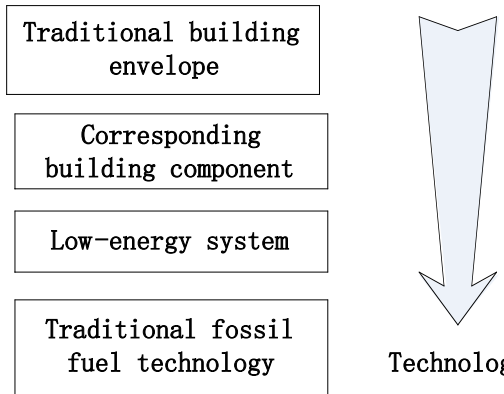

Technology

Fig. (2). Design procedure and corresponding technology. 
Table 1. Software type of BIM.

\begin{tabular}{|c|c|c|}
\hline Create BIM Software & \multicolumn{2}{|c|}{ Utilize BIM Software } \\
\hline \hline BIM core modeling software & Sustainable analysis software & Electromechanical analysis software \\
\hline Scheme design software & Structural analysis software & Visualized software \\
\hline Geometric modeling software connecting to BIM & Model inspection software & Model collision software \\
\hline & Operation management software & Release and review software \\
\hline
\end{tabular}

of renewable resource and indoor environment as well as design principle. Finally, the type of BIM software should be defined, the details of which are shown as in Table $\mathbf{1 .}$

\subsubsection{Reasonable Arrangement}

The project budget and cost are determined by proprietor, but building system and energy equipment should be taken as the starting point during actual design process. Due to the essential gap between separate construction transaction form and cost management, long-term development mode and application mechanism should be established to analyze variation system efficiently. To achieve definite guarantee for innovation project, definite energy development goal should be proposed during the bidding and design process. During the project development process, analysis should be made among building, structure and energy environment and integration analysis on design form should be conducted in accordance with the established design mode and trend. Moreover, design idea can be deepened by referring to the existing objective [4].

\subsubsection{Design form}

Based on the complexity of BIM process, relevant structures and modes should be analyzed at the early stage of construction. In terms of cost estimation system involved in application process, design elements, and relevant criterions and standards, optimization analysis should be conducted to the appearance and interior structure of application program and the energy supply scheme and application mode should be determined in accordance with the actual situation. Finally, the key point of design and development should be defined, and the influencing mechanism for the horizontal and vertical development of building envelope as well as the basic formation specification of design normative system and the performance of sports building should be mastered. As one of the key elements, scheme designer must analyze the functional structure, system restriction and objective value efficiently [5].

\subsection{Analysis on Preliminary Design Mode}

Simple calculation form can be taken as the application standard at initial design stage and the concept of integrated building should be understood in the solution to building design. During the design process at this stage, the concept and design form of integrated building can be comprehended through sketch and detailed calculation mode. Parameter values should be correspondingly changed during systematic design process and necessary design and application should be conducted to additional building's external wall. Professional team can adopt additional thermal insulation layer of hard board and facade of external wall, or they can install LOW-E coating spectral selection to the windows on southern and western walls. The relative impact of these substitutes can be quantized through the energy consumption simulation of operation and relative cost can be analyzed based on the result of savings. During specific design process, the application software and equipment of the system may affect the installation system and staged design objective can be determined at the final design stage [6]. Technology equipment and device system involve the final design method and application technology. To understand the detailed drawing and calculation mode, the application program of pipe engineering and electronic system must be comprehended. The specific virtual drawing of sports building is shown as in Fig. (3).

\subsection{Analysis on the Design Mechanism of Construction Drawing}

Construction drawing is designed at the last stage and reasonable analysis and application should be conducted through technological scheme transformation and joint contracting reform. Participators and key designers must define design essentials, confirm solutions in the practical application of staged design, and have some knowledge of the specification, model and size of product. And node details should be known if necessary. Construction company, supplier and product manufacture should understand relevant design procedure. Therefore, the actual role of extra information should be understood in actual design and application practice [7]. The design team must comprehend energy performance and environmental index according to the normative foundation. And efficient analysis must be conducted to construction progress when the bidding document is made and implemented. At the last design stage, the design technology becomes more and more complex as construction project type increases. For the requirements of proprietor, the detail list of project should be provided at design stage. The specific design table is shown as in Table 2.

Besides, the software and functional system of BIM can be utilized to analyze the generation table comprehensively. Because of the essential difference among structural mate- 


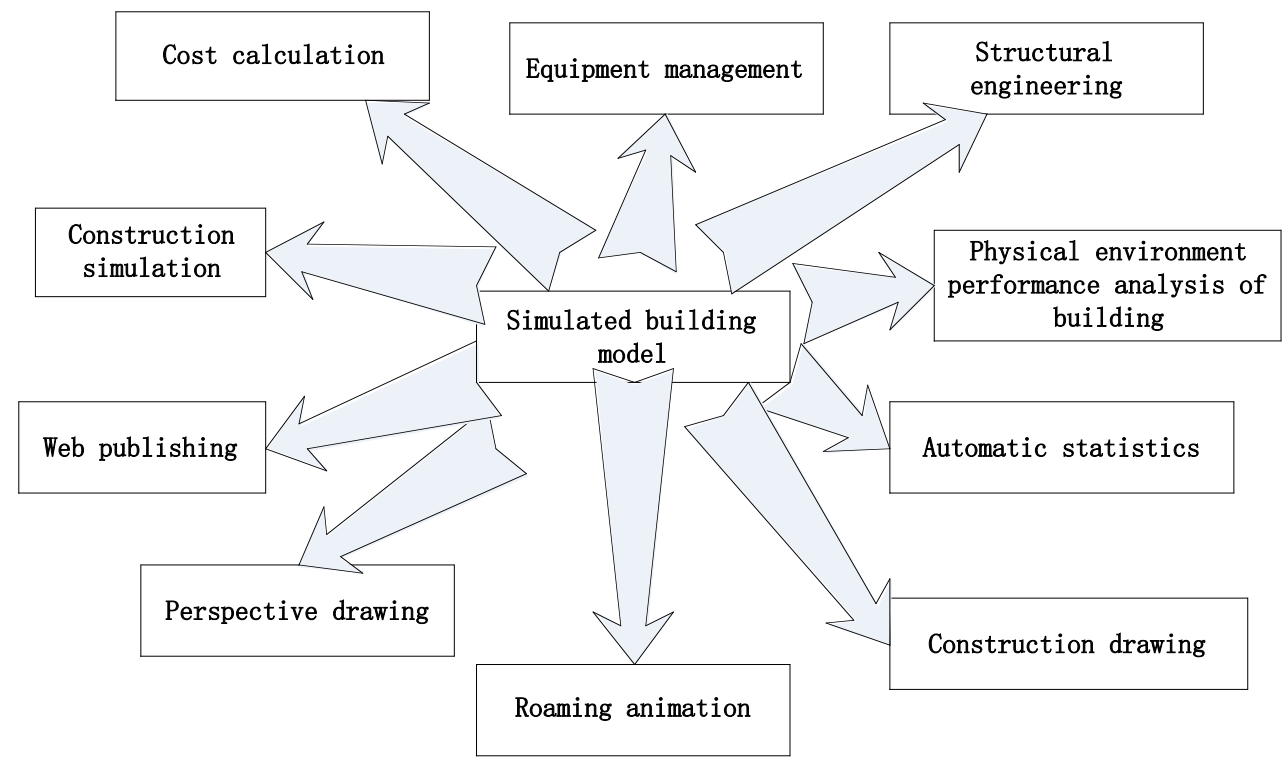

Fig. (3). Design mode of simulated figure for sports building.

Table 2. Situation analysis of procedure design.

\begin{tabular}{|c|c|c|c|c|}
\hline Procedure & Heating & Cooling & Lighting & Ventilation \\
\hline \hline Basic design & Air infiltration & Color of facade & Interior decoration & Building form \\
\hline Climate design & Direct acquisition & Evaporative cooling & Skylight & Unilateral design \\
\hline Equipment design & Radiator & $\begin{array}{c}\text { Air conditioning refrigera- } \\
\text { tion }\end{array}$ & Lighting equipment & Mechanical ventilation \\
\hline
\end{tabular}

rial, plastering material and system setup, the occurrence probability of problem must be minimized at design stage and efficient analysis software and program should be used to conduct analysis and application appropriately [8]. Threedimensional design objective should be used to change the thinking and form of application, thus mastering the overall form of building design.

\section{CONCLUSION}

On account of various problems in the practice of BIM design structure, the original design process must be abandoned to reduce the impact of influencing factors and sports building design should also be comprehended in accordance with new development idea and application strategy. With the continuous improvement of people's life level in recent years, integrated construction is taken as a solid development platform. To improve the application effect of BIM, reasonable and efficient analysis should be conducted to design process and application standard by virtue of the integration platform, covering BIM, software, relevant technology cluster, etc. And the conclusion is accordingly achieved: "synergy" is the uppermost characteristic and concrete expression of integrated design. Restricted by many factors, BIM application system shows less practicability. Therefore, sports building can realize sustainable development only by taking green design index as media and being supported by BIM system.

\section{CONFLICT OF INTEREST}

The authors confirm that this article content has no conflict of interest.

\section{ACKNOWLEDGEMENTS}

Declared none.

\section{REFERENCES}

[1] M. Liu, L. Zhang, and J. Liao, "Study on the Development and Promotion of Green Building" Beijing: Economic Management Publishing House, vol. 19, no. 10, pp. 168-169, 2012.

[2] W. Xu, "Digital Construction - Student's Building Design Works," Beijing: China Architecture \& Building Press, vol. 29, no. 10, pp. 390-392, 2012

[3] C. Yu, "Building Design and Construction Based on Digital Information Integration," Beijing: China Architecture \& Building Press, vol. 28 , no. 2, pp. 41-52, 2011.

[4] X. Zeng, and A. Zhao, "Study on Application of Building Energyconservation Design Based on BIM Technology," Journal of Chongqing University, vol. 28, no. 2, pp. 33-35, 2011.

[5] Z. Luo, and D. Xie, "Study on Application of Sustainable Building Design Based on BIM Technology," Architecture \& Culture, no. 2, pp. 100-103, 2010.

[6] Y. Gu, “Intelligent Technology Is Important Basis for Supporting Green Buildings," Intelligent Building \& City Information, no. 3, pp. 12-15, 2011.

[7] P. Peng, "Study on BIM Design Process Based on Detailed Drawing Description and Building Performance," Analysis Huazhong 
University of Science and Technology, vol. 29, no. 10, pp. 290-293, 2010.
[8] O. Dong, and Y. Xing, "How BIM Facilitates the Transformation of Design Technique," Engineering Construction and Design, vol. 19, no. 10, pp. 90-93, 2012.

Received: June 10, 2015

Revised: July 29, 2015

Accepted: August 15,2015

(C) Zhu and Tu; Licensee Bentham Open.

This is an open access article licensed under the terms of the (https://creativecommons.org/licenses/by/4.0/legalcode), which permits unrestricted, noncommercial use, distribution and reproduction in any medium, provided the work is properly cited. 